\title{
PENGARUH PENGGUNAAN BERBAGAI NUTRISI PADA PERTUMBUHAN TANAMAN SELADA KERITING (Lactuca sativa L.) HIDROPONIK SISTEM WICK
}

\section{The Effect Of Use Various Nutrients On Plant Growth Of Hydroponic Lettuce Plants (Lactuca satica L.) in Wick System}

\author{
Elinda Nur Aziza Setyaputri ${ }^{1 \star}$, Rika Despita ${ }^{1}$, Joko Gagung $\mathbf{S}^{1}$ \\ Jurusan Penyuluhan Pertanian Berkelanjutan \\ Politeknik Pembangunan Pertanian Malang \\ JI. Dr. Cipto 144 A Bedali Lawang Malang 65215 Jawa Timur, Indonesia \\ ${ }^{*}$ Korespondensi penulis : E-mail : elindaaza@gmail.com
}

Diterima: September 2020

Disetujui terbit: Desember 2020

\begin{abstract}
Lettuce plant is a vegetable plant which has many benefits. On the contrary, many urban farmers facing problems due to conventional cultivation caused by limited land. Hydroponics is an alternative to cultivate in limited spaces. Providing adequate nutrition in hydroponic system cultivation can help the productivity of lettuce plants. The study aimed to determine the effect of hydroponic nutrition with liquid organic fertilizers on the growth of lettuce plants. Research was conducted field laboratory of Malang Agricultural Development Polytechnic from March to July 2020. Data was analyzed using Completely Randomized Design (CRD) with single factor. The result with the best treatment for the variabels of plants height and number of leaf in the nutritional composition (P1) is 100\% ABmix. Fresh weight was measured at 35 DAP (Day After Planting), the highest was (P1) is 65,75 grams. Plants that are given nutrients from biourine liquid organic fertilizer without foliar fertilizer have a chance of being able to balance ABmix nutrition from plant height, number of leaves and plant fresh weight. Keywords: lettuce, hydroponics, nutrition of hydroponics
\end{abstract}

\begin{abstract}
ABSTRAK
Tanaman selada merupakan tanaman yang memiliki banyak manfaat dan kegunaan. Namun banyak petani perkotaan terkendala untuk budidaya secara konvensional karena keterbatasan lahan yang dimiliki. Hidroponik merupakan alternatif budidaya pada lahan sempit dengan pemanfaatan pekarangan rumah. Pemberian nutrisi yang tepat pada budidaya sistem hidroponik dapat meningkatkan produktivitas tanaman selada. Penelitian ini bertujuan untuk mengetahui pengaruh nutrisi hidroponik dengan pupuk organik cair terhadap pertumbuhan tanaman selada. Penelitian ini dilaksanakan di lahan praktik milik Politeknik Pembangunan Pertanian Malang pada bulan Maret-Juli 2020. Penelitian ini adalah percobaan non faktorial yang menggunakan RAL (Rancangan Acak Lengkap). Hasil penelitian yang menunjukkan adanya perlakuan terbaik dari variabel tinggi tanaman dan jumlah daun terdapat pada komposisi nutrisi (P1) 100\% AB mix. Bobot segar tanaman diukur pada 35 HST (masa panen) tertinggi terdapat pada (P1) yaitu 65,75 gram. Tanaman yang diberi nutrisi pupuk organik cair biourin tanpa pupuk daun memiliki peluang hasil yang mampu menyeimbangi pemberian nutrisi ABmix baik dari tinggi tanaman, jumlah daun, dan bobot segar tanaman.

Kata Kunci: selada, hidroponik, nutrisi hidroponik
\end{abstract}




\section{PENDAHULUAN}

Kebutuhan sayuran semakin meningkat seiring bertambahnya kebutuhan gizi di Indonesia. Salah satu sayuran yang memiliki gizi tinggi yaitu sayuran selada dengan nilai ekonomis yang tinggi (Purwanto, 2005). Minimnya ketersediaan lahan di banyak tempat di Indonesia menjadi faktor pembatas karena adanya alih fungsi lahan menjadi bangunan industri maupun non-industri. Permasalahan lahan sempit menjadi kendala dalam kegiatan berbudidaya yang dirasakan oleh masyarakat Indonesia. Namun, dalam permasalahan lahan sempit menjadi inovasi bagi petani dalam mengembangkan karyanya dalam kegiatan berbudidaya. Pemanfaatan lahan pekarangan merupakan salah satu solusi dari permasalahan lahan sempit. Selain itu, pemanfaatan pekarangan juga memiliki potensi dalam penyediaan bahan pangan dalam kebutuhan rumah tangga. Budidaya di lahan pekarangan juga dapat memberikan banyak manfaat untuk keberlanjutan ekonomi maupun ekologi di wilayah perkotaan (Fauzi et al., 2016).

Pemerintah memberikan dukungan dalam melakukan budidaya di lahan pekarangan melalui program
KRPL (Kawasan Rumah Pangan Lestari) yang dipertegas dalam peraturan menteri pertanian nomor : 15/Permentan/OT.140/2/2013 tentang Diversifikasi dan Ketahanan Pangan yaitu pedoman umum KRPL melalui pemanfaatan pekarangan dan upaya dalam memberdayakan kegiatan rumah tangga.

Hidroponik merupakan metode tanam yang tepat dalam pemanfaatan lahan pekarangan. Salah satu kelebihan bercocok tanam menggunakan metode hidroponik yaitu tanaman tetap akan tumbuh pada ruang terbatas. Hidroponik merupakan budidaya dengan media air, sehingga air pada media harus memiliki takaran nutrisi yang tepat. Sejauh ini penggunaan nutrisi pada budidaya hidroponik masih menggunakan nutrisi anorganik yang jika digunakan secara berkelanjutan akan memberikan dampak negatif terhadap pengkonsumsi hasil panen maupun pada lingkungan. Solusi yang dibutuhkan dalam menekan dampak negatif akibat penggunaan nutrisi anorganik yaitu menggunakan nutrisi organik. Penggunaan nutrisi organik dapat berupa pupuk organik cair. Penelitian dilakukan untuk menentukan konsentrasi nutrisi terbaik yang mampu menekan penggunaan 
nutrisi anorganik dan pertumbuhan tanaman yang optimal.

\section{BAHAN DAN METODE PENELITIAN}

Penelitian dilaksanakan di kebun IFS (Integrated Farming System) milik Politeknik Pembangunan Pertanian Malang pada bulan Maret-Juli 2020.

Alat yang digunakan antara lain alat tulis kantor, kotak es krim, TDS meter, alat ukur pH, gelas ukur, suntikan nutrisi, timbangan analitik, net pot, bak perkecambahan, kain flannel, sprayer, dan pemotong. Bahan yang digunakan adalah benih selada keriting, pupuk organik cair GDM, AB mix, biourin, pupuk daun, asam fosfat, dan rockwool.

Penelitian ini adalah percobaan non faktorial yang menggunakan $\mathrm{RAL}$ (Rancangan Acak Lengkap) dengan 10 perlakuan nutrisi yaitu (P1) $A B$ mix $100 \%$ dengan pupuk daun, (P2) 50\% ABmix : 50\% POC GDM dengan pupuk daun, (P3) 100\% POC GDM dengan pupuk daun, (P4) 50\% ABmix : 50\% Biourin dengan pupuk daun, (P5) $100 \%$ Biourin dengan pupuk daun, (P6) 100\% Biourin, (P7) 50\% ABmix : 50\% POC GDM, (P8) 100\% POC GDM, (P9) 50\% ABmix : 50\% Biourin dan (P10) 100\% Biourin. Pengamatan pertumbuhan diamati setiap minggu (7, 14, 21, 27, 28, 35 HST) dengan variabel tinggi tanaman, jumlah daun, dan bobot basah tanaman. Data yang diperoleh diolah dengan menggunakan ANOVA (Analysis of Varians) pada taraf 5\%. Hasil data yang menunjukkan pengaruh nyata dilanjutkan dengan uji DMRT (Duncan Multiple Range Test) dengan taraf $5 \%$.

Pelaksanaan Penelitian

\section{Rangkaian Hidroponik Sistem Wick}

Rangkaian hidroponik sistem wick menggunakan kotak es krim dengan kapasitas air 8 liter, tinggi kotak $24 \mathrm{~cm}$, lebar kotak bagian bawah $19 \mathrm{~cm}$ dan lebar kotak bagian atas 22 $\mathrm{cm}$. Bagian kotak yang akan ditanami dilubangi menggunakan bor listrik diameter $5 \mathrm{~cm}$. Kotak es krim yang sudah disiapkan untuk penanaman selada keriting disusun sesuai dengan denah percobaan penelitian pada lahan penelitian.

1) Media semai/rockwool dipotong dengan ukuran $3 \times 3 \mathrm{~cm}$

2) Rockwool disusun pada bak pembenihan dan kemudian direndam air hingga rockwool basah

3) Rockwool dilubangi dan diberi 1-2 benih selada keriting

\section{Nutrisi}

Bak penampungan air dan nutrisi memiliki kapasitas 50 liter. Sebelum campuran nutrisi dimasukkan ke 
dalam masing-masing kotak es krim, nutrisi dicampur terlebih dahulu sesuai dengan perlakuan penelitian baru kemudian dimasukkan ke dalam kotak tersebut sebanyak 6 liter nutrisi.

\section{Pemeliharaan}

Pemeliharaan tanaman selada hidroponik sistem wick dengan cara:

1) Membersihkan gulma yang mengganggu pada media tanam yang terdapat pada box penanaman maupun di sekitar tanaman selada

2) Menambah nutrisi dan air apabila volume air sudah mulai berkurang

3) Menjaga kebersihan bak dan air pada box penanaman.

4) Pengadukan air nutrisi menggunakan tongkat pengadukan yang bertujuan untuk memecah air agar memberikan oksigen

5) Penyemprotan pupuk daun (GDM) pada tanaman selada setiap 7 hari sekali

\section{Pemanenan}

Pemanenan dilakukan pada umur 35 HST dengan cara manual. Kriteria panen selada keriting sangat subjektif. Panen selada dilakukan sebelum tanaman berbunga. Setelah pemanenan, tanaman ditimbang guna mengukur bobot basah tanaman.
Pemanenan harus dilakukan dengan cepat karena selada merupakan tanaman yang dimanfaatkan daunnya, sehingga harus terjaga kualitas daunnya.

\section{HASIL DAN PEMBAHASAN}

\section{Tinggi Tanaman}

Tinggi tanaman adalah salah satu indikator pertumbuhan tanaman selada keriting hidroponik sistem wick. Rata-rata tinggi tanaman selada keriting disajikan pada Tabel 1.

Data yang ditampilkan pada Tabel 1 menunjukkan bahwa penggunaan berbagai nutrisi pada tanaman selada keriting hidroponik sistem wick pada 1 MST tidak terdapat perbedaan yang signifikan. Meskipun demikian, pada 2 hingga 4 MST. Terdapat perbedaan yang signifikan. Pada 2 MST, rata-rata tinggi tanaman yang tertinggi yakni pada perlakuan nutrisi 100\% ABmix dengan pupuk daun (P1) yang memiliki nilai $7,55 \mathrm{~cm}$. Pada 3 MST rata-rata tertinggi yaitu terdapat pada penggunaan 100\% ABmix dengan pupuk daun (P1) yang memiliki nilai $10,2 \mathrm{~cm}$. Sedangkan untuk 4 MST rata-rata tinggi tanaman yang tertinggi terdapat pada penggunaan nutrisi $100 \%$ ABmix dengan pupuk daun (P1) yang memiliki nilai $17,2 \mathrm{~cm}$. 
Tabel 1 Tinggi tanaman selada keriting pada perlakuan berbagai nutrisi hidroponik sistem wick $(\mathrm{cm})$

\begin{tabular}{|c|c|c|c|c|c|c|c|c|}
\hline \multirow{2}{*}{\multicolumn{2}{|c|}{ Perlakuan }} & \multicolumn{7}{|c|}{ Umur Pengamatan (MST) } \\
\hline & & \multirow{2}{*}{$\frac{1}{5,00}$} & \multicolumn{2}{|c|}{2} & \multicolumn{2}{|c|}{3} & \multicolumn{2}{|l|}{4} \\
\hline P1 & $(100 \%$ ABmix+PD) & & 7,55 & $d$ & 10,2 & c & 17,2 & $\mathrm{f}$ \\
\hline P2 & (50\%ABmix+50\%POCGDM+PD) & 3,25 & 4,90 & $a b$ & 7,37 & a & 8,76 & a \\
\hline P3 & $(100 \% P O C$ GDM+PD) & 3,72 & 4,50 & $a b$ & 7,00 & a & 8,75 & a \\
\hline P4 & (50\%ABmix+50\%Biourin+PD) & 3,80 & 5,15 & $a b$ & 9,25 & bc & 11,8 & bcd \\
\hline P5 & (100\%Biouri & 4,05 & 5,75 & bc & 8,37 & $a b$ & 12,0 & bcd \\
\hline P6 & (100\%ABmix) & 4,72 & 7,02 & $\mathrm{~cd}$ & 9,87 & bc & 15,3 & ef \\
\hline P7 & (50\%ABmix+50\%POCGDM) & 3,80 & 3,82 & a & 7,00 & a & 10,2 & $a b$ \\
\hline P8 & (100\%POC GDM) & 3,67 & 4,60 & $a b$ & 7,50 & a & 11,3 & bc \\
\hline P9 & (50\%ABmix+50\%Biourin) & 3,80 & 5,50 & b & 8,25 & $a b$ & 13,6 & cde \\
\hline P10 & (100\%Biourin) & 4,06 & 5,57 & b & 9,37 & $\mathrm{bc}$ & 14,0 & de \\
\hline & & & 21 & & 17,4 & & 12,2 & \\
\hline
\end{tabular}

Keterangan: Angka yang diikuti huruf yang sama pada kolom yang sama menunjukkan tidak terdapat perbedaan yang nyata antara perlakuan

Hasil olah data yang tersaji pada

Tabel 1 di atas, didapatkan hasil terbaik terdapat pada perlakuan penggunaan nutrisi $100 \%$ ABmix dengan pupuk daun (P1). Menurut Muhadiansyah (2016), perbedaan yang nyata dalam penggunaan nutrisi ABmix dikarenakan unsur hara yang terkandung tergolong lengkap, sehingga penggunaan nutrisi pupuk organik cair belum dapat menggantikan nutrisi ABmix. Menurut Wiekandyne (2012) dalam Pramatasari (2016) adanya penambahan unsur $\mathrm{N}$ pada tanaman mampu memaksimalkan proses pertumbuhan tanaman pada pertumbuhan vegetatif yang berpengaruh pada tinggi tanaman. Pada fase pertumbuhan vegetatif, nitrogen mampu memacu pertumbuhan tanaman terutama pada batang (Gardner et al. 1991 dalam Rizal, 2017).

\section{Jumlah Daun}

Jumlah helai daun termasuk salah satu indikator pertumbuhan tanaman selada keriting hidroponik sistem wick. Rata-rata jumlah daun disajikan pada Tabel 2

Tabel 2 menjelaskan bahwa penggunaan berbagai nutrisi terhadap tanaman selada keriting hidroponik sistem wick terdapat adanya perbedaan yang signifikan pada 1 hingga 4 MST. Diketahui bahwa pada 1 MST rata-rata jumlah daun yang tertinggi terdapat pada penggunaan nutrisi 100\% ABmix dengan pupuk daun (P1) yang memiliki nilai 5,25 helai. Pada 2 MST rata-rata jumlah daun yang tertinggi terdapat pada penggunaan nutrisi 100\% ABmix dengan pupuk daun (P1) yang memiliki 
nilai 6,60 helai. Pada 3 MST rata-rata jumlah daun yang tertinggi terdapat pada penggunaan nutrisi 100\% ABmix dengan pupuk daun (P1) yang memiliki nilai 8,50 helai. Sedangkan untuk 4
MST rata-rata tertinggi dari variabel jumlah daun adalah penggunaan nutrisi 100\% ABmix dengan pupuk daun (P1) adalah 10,2 helai.

Tabel 2 Jumlah daun selada keriting pada perlakuan berbagai nutrisi hidroponik sistem wick

\begin{tabular}{|c|c|c|c|c|c|c|c|c|c|}
\hline \multirow{2}{*}{\multicolumn{2}{|c|}{ Perlakuan }} & \multicolumn{8}{|c|}{ Umur Pengamatan (MST) } \\
\hline & & \multicolumn{2}{|c|}{1} & \multicolumn{2}{|c|}{2} & \multicolumn{2}{|c|}{3} & \multicolumn{2}{|c|}{4} \\
\hline $\mathrm{P} 1$ & $(100 \%$ ABmix+PD) & 5,25 & c & 6,60 & b & 8,50 & C & 10,2 & c \\
\hline P2 & $(50 \% A B m i x+50 \%$ POCGDM+PD) & 3,80 & a & 4,50 & a & 6,78 & $a b$ & 7,07 & a \\
\hline P3 & $(100 \%$ POC GDM+PD) & 3,60 & $a$ & 4,55 & a & 6,87 & $a b$ & 7,75 & $a b$ \\
\hline P4 & $(50 \%$ ABmix $+50 \%$ Biourin+PD) & 4,40 & $a b c$ & 4,78 & a & 7,22 & $a b$ & 8,02 & $a b$ \\
\hline P5 & (100\%Biourin+PD) & 4,13 & $a b$ & 5,07 & b & 7,32 & $a b$ & 8,12 & $a b$ \\
\hline P6 & (100\%ABmix) & 4,88 & bc & 6,80 & a & 7,92 & $\mathrm{bc}$ & 9,20 & bc \\
\hline P7 & (50\%ABmix+50\%POCGDM) & 4,08 & $a b$ & 4,72 & a & 6,55 & a & 7,05 & a \\
\hline P8 & $(100 \% P O C$ GDM) & 3,73 & a & 4,50 & a & 6,32 & a & 7,12 & a \\
\hline P9 & (50\%ABmix+50\%Biourin) & 3,98 & $a b$ & 4,78 & a & 7,17 & $a b$ & 7,72 & $a b$ \\
\hline P10 & (100\%Biourin) & 4,83 & $b c$ & 5,50 & a & 7,38 & $a b c$ & 8,78 & $\mathrm{~b}$ \\
\hline & KK & & 20 & 11 & & & & & \\
\hline
\end{tabular}

Keterangan: Angka yang diikuti huruf yang sama pada kolom yang sama menunjukkan tidak terdapat perbedaan yang nyata antara perlakuan

Nutrisi ABmix memiliki unsur hara yang lengkap yang dibutuhkan tanaman terutama unsur Nitrogen $(\mathrm{N})$ yang dibutuhkan tanaman dalam jumlah banyak untuk membantu pembelahan sel pada daun menurut Djafar (2013) dalam Bahzar (2018). Hasil penelitian pada pemberian POC GDM menunjukkan pertumbuhan jumlah daun tanaman yang rendah. Pemberian nutrisi dalam jumlah yang tepat dapat menentukan baik atau tidaknya pertumbuhan tanaman selada keriting. Sehingga dengan penambahan pupuk daun yang diaplikasikan melalui penyemprotan pada daun secara langsung mampu memaksimalkan

pertumbuhan tanaman selada keriting. Menurut Sembiring (2018), penggunaan pupuk daun yang diaplikasikan langsung pada tanaman selada dapat mempengaruhi pertumbuhan tanaman karena penyerapan nutrisi secara langsung oleh daun. Hasil penelitian yang dilakukan menunjukkan bahwa pupuk daun yang diaplikasikan tidak berpengaruh nyata pada jumlah daun setiap perlakuan. Hal ini diduga karena adanya faktor eksternal yang mempengaruhi efek pemberian pupuk daun pada tanaman. 


\section{Berat Basah}

Bobot/berat basah tanaman selada keriting merupakan indikator pertumbuhan tanaman selada pada budidaya hidroponik sistem wick. Rata-rata bobot basah tanaman disajikan dalam Tabel 3.

Tabel 3 menjelaskan bahwa hasil dari bobot basah tanaman menunjukkan perbedaan yang signifikan antar perlakuan. Rata-rata yang tertinggi dari bobot basah tanaman masih terdapat pada penggunaan nutrisi $100 \%$ ABmix dengan pupuk daun (P1) yang memiliki nilai 65,75 gram. Penyerapan unsur hara yang baik dapat diindikasi melalui bobot basah tanaman. Hasil berat tanaman yang diukur menunjukkan bahwa penyerapan unsur hara semakin besar. Penggunaan nutrisi biourin memiliki nilai rata-rata bobot basah tanaman yang hampir sama dengan penggunaan nutrisi ABmix. Sehingga nutrisi dengan campuran biourin dapat dijadikan rekomendasi penggunaan nutrisi hidroponik.

Tabel 3 Rata-rata berat basah tanaman selada keriting pada perlakuan berbagai nutrisi hidroponik sistem wick

\begin{tabular}{|c|c|c|c|}
\hline \multicolumn{2}{|r|}{ Perlakuan } & \multirow{2}{*}{$\begin{array}{c}\text { Rata-Rata } \\
65,75\end{array}$} & \multirow{2}{*}{$\frac{\text { Notasi }}{d}$} \\
\hline $\mathrm{P} 1$ & $(100 \%$ ABmix+PD) & & \\
\hline P2 & (50\%ABmix+50\%POCGDM+PD) & 28,00 & $\mathrm{a}$ \\
\hline P3 & $(100 \% P O C$ GDM+PD) & 28,00 & $\mathrm{a}$ \\
\hline P4 & (50\%ABmix+50\%Biourin+PD) & 47,50 & bc \\
\hline P5 & $(100 \%$ Biourin+PD) & 50,25 & $\mathrm{c}$ \\
\hline P6 & $(100 \% A B m i x)$ & 61,75 & $\mathrm{~cd}$ \\
\hline P7 & (50\%ABmix+50\%POCGDM) & 35,25 & $a b$ \\
\hline P8 & $(100 \%$ POC GDM) & 26,75 & $\mathrm{a}$ \\
\hline P9 & (50\%ABmix+50\%Biourin) & 54,50 & $\mathrm{~cd}$ \\
\hline P10 & (100\%Biourin) & 56,75 & $\mathrm{~cd}$ \\
\hline & $\mathrm{KK}$ & & \\
\hline
\end{tabular}

Keterangan: Angka yang diikuti huruf yang sama pada kolom yang sama menunjukkan tidak terdapat perbedaan yang nyata antara perlakuan

\section{SIMPULAN DAN SARAN}

Pemberian nutrisi ABmix adalah pemberian nutrisi yang mampu mencapai hasil optimal pada variabel pengamatan tinggi tanaman, jumlah daun dan bobot basah tanaman dari penggunaan nutrisi lainnya pada pertumbuhan tanaman selada hidroponik sistem wick. Penggunaan nutrisi biourin tanpa pupuk daun mampu menyeimbangi hasil dari penggunaan ABmix. Sehingga 
penggunaan nutrisi biourin dapat dijadikan rekomendasi sebagai nutrisi organik untuk budidaya sistem hidroponik. Dari hasil pelaksanaan penelitian didapat bahwa pengaruh terbaik terhadap pertumbuhan tanaman selada keriting hidroponik sistem wick adalah penggunaan nutrisi 100\% ABmix dengan pupuk daun (P1), 100\% ABmix tanpa pupuk daun (P6), 50\% ABmix : $50 \%$ Biourin tanpa pupuk daun (P9) dan 100\% Biourin tanpa pupuk daun (P10).

Berdasarkan hasil penelitian yang dilaksanakan perlu adanya pelaksanaan penelitian lebih lanjut tentang pengaruh penggunaan berbagai nutrisi pada tanaman selada keriting hidroponik sistem wick ini untuk dapat menggantikan nutrisi anorganik secara keseluruhan yang mampu menekan pertumbuhan tanaman secara optimal dengan kandungan unsur hara yang lengkap.

\section{DAFTAR PUSTAKA}

Bahzar HM, Santosa M. 2018. Pengaruh Nutrisi dan Media Tanam Terhadap Pertumbuhan Dan Hasil Tanaman Pakcoy (Brassica rapa L. var. chinensis) Dengan Sistem Hidroponik Sumbu. Jurusan Budidaya Pertanian. Fakultas Pertanian.
Universitas Brawijaya. Malang. Jurnal Produksi Tanaman. Vol. 6 No. 7. (1273-1281).

Fauzi AR, Ichniarsyah AN, Agustin H. 2016. Pertanian Perkotaan, Urgensi, Peranan, dan Praktik Terbaik. Urban Agrivulture. Program Studi Agroekoteknologi. Universitas Trilogi. Jakarta Jalan Kampus Tri. Jurnal Agroteknologi, Vol 10 No. 01.

Muhadiansyah O. 2016. Efektivitas Pencampuran Pupuk Organik Cair Dalam Nutrisi Hidroponik Pada Pertumbuhan dan Produksi Tanaman Selada (Lactuca sativa L.) Jurusan Agroteknologi. Universitas Djuanda. Bogor. Jurnal Agronida ISSN 2442-2541. Vol. 2 Nomor 1.

Purwanto EB. 2005. Pengaruh Konsentrasi Dan Frekuensi Pemberian Larutan Nutrisi Terhadap Pertumbuhan Dan Hasil Selada (Lactuca sativa) Secara Hidroponik. Fakultas Pertanian. Universitas Muhammadiyah Jember. April Rizal S. 2017. Pengaruh Nutriasi Yang

Diberikan Terhadap Pertumbuhan Tanaman Sawi Pakcoy (Brassica rapa L.) Yang 
Ditanam Secara Hidroponik.

Jurusan Biologi. Fakultas MIPA.

Universitas PGRI Palembang.

Sainmatika. ISSN. 1829 586X.

Vol 14. No.1 (38-44).

Sembiring G. 2018. Pengaruh Komposisi Nutrisi Dan Pupuk

Daun Pada Pertumbuhan Dan

Hasil Tanaman Pakcoy

(Brassica rapa $L$ var. Chinensis)

Sistem Hidroponik Rakit Apung.

[Skripsi]. Fakultas Pertanian.

Universitas Brawijaya Malang.

Journal of Agricultural Science.

3(2): $103-109$. 